\title{
The Vector Potential Far from a Magnetic Dipole
}

\section{Karlsson, Per W.}

\section{Published in:}

American Journal of Physics

Link to article, DOI:

10.1119/1.1988076

Publication date:

1972

\section{Document Version}

Publisher's PDF, also known as Version of record

Link back to DTU Orbit

Citation (APA):

Karlsson, P. W. (1972). The Vector Potential Far from a Magnetic Dipole. American Journal of Physics, 40(4), 633-633. https://doi.org/10.1119/1.1988076

\section{General rights}

Copyright and moral rights for the publications made accessible in the public portal are retained by the authors and/or other copyright owners and it is a condition of accessing publications that users recognise and abide by the legal requirements associated with these rights.

- Users may download and print one copy of any publication from the public portal for the purpose of private study or research.

- You may not further distribute the material or use it for any profit-making activity or commercial gain

- You may freely distribute the URL identifying the publication in the public portal

If you believe that this document breaches copyright please contact us providing details, and we will remove access to the work immediately and investigate your claim 


\section{LETTERS TO THE EDITOR}

The Vector Potential Far from a Magnetic Dipole PER W. KARLSSON

Department of Physics

The Technical University

Lyngby, Denmark

(Received 29 October 1971)

Recently, the vector potential of a magnetic dipole was discussed by $\mathrm{Rao}^{1}$; in particular, the approximate expression which is valid when the field point is far from the dipole was found. It is interesting to note that this expression can be obtained by a simpler procedure.

A point in the vicinity of the current loop $C$ is taken as origin for the vectors $\mathbf{x}, \mathbf{x}^{\prime}$ to the fixed field point $P$ and the variable point $P^{\prime}$, respectively. Then, to the first order, the reciprocal of the distance between $P$ and $P^{\prime}$ is

$$
R^{-1}=|\mathbf{x}|^{-1}+\mathbf{x}^{\prime} \cdot \mathbf{g}, \quad \mathbf{g} \equiv \mathbf{x} /|\mathbf{x}|^{3} .
$$

We now utilize Stokes' theorem and the fact that when $\mathbf{g}$ is constant $\nabla^{\prime}\left(\mathbf{x}^{\prime} \cdot \mathbf{g}\right)=\mathbf{g}$, to transform the vector potential:

$$
\begin{aligned}
\mathbf{A} & =\frac{\mu_{0} I}{4 \pi} \oint_{C} \frac{d \mathbf{x}^{\prime}}{R} \\
& =\frac{\mu_{0} I}{4 \pi}\left[|\mathbf{x}|^{-1} \oint_{C} d \mathbf{x}^{\prime}+\oint_{C} d \mathbf{x}^{\prime}\left(\mathbf{x}^{\prime} \cdot \mathrm{g}\right)\right] \\
& =\frac{\mu_{0} I}{4 \pi}\left[0+\int_{S} d \mathbf{S} \times \nabla^{\prime}\left(\mathbf{x}^{\prime} \cdot \mathrm{g}\right)\right] \\
& =\frac{\mu_{0} I}{4 \pi} \int_{S} d \mathbf{S} \times \mathbf{g} .
\end{aligned}
$$

When the magnetic dipole moment $\mathrm{m}$ is introduced we finally obtain

$$
\mathbf{A}=\left(\mu_{0} / 4 \pi\right)\left(\mathbf{m} \times \mathbf{x} /|\mathbf{x}|^{3}\right) .
$$

${ }^{1}$ N. D. Rao, Amer. J. Phys. 39, 1276 (1971).

\section{Re: Schlegel's Bohrian Reply to EPR: A Comment}

\section{A. HOOKER}

Department of Philosophy

The University of Western Ontario

London, Canada

(Received 7 June 1971; revised 6 December 1971)

In a recent letter ${ }^{1}$ Schlegel argues that my recent demand $^{2}$ for a physically plausible resolution of the Einstein-Podolsky-Rosen paradox is superfluous because Bohr has already provided that resolution many years ago. I have since had occasion to examine the Einstein-Podolsky-Rosen paradox and Bohr's quantum philosophy, in some detail, ${ }^{3}$ so I shall not go into these matters here. What I want to do here is to comment on the detail of Schlegel's argument.

Schlegel's essential point seems to be this: Arguments which establish the EPR paradox or its equivalent all employ wave functions which are incompatible with the Heisenberg uncertainty relations. For this reason, according to Schlegel, it is physically impossible to prepare atomic systems in quantum states correctly represented by any of the wave functions employed in such arguments.

Now this way of stating the matter leads to a very curious conclusion. Since there can be no doubt that the wave functions employed in the arguments under discussion each satisfy Schrödinger's wave equation, Schlegel seems to be claiming that there are wave functions which satisfy Schrödinger's equation and which yet violate the Heisenberg uncertainty relations. But this suggests that the mathematical structure of quantum theory is inconsistent. Since this conclusion seems pretty unlikely to be true-at least in the rather obvious sense required here-we conclude instead that this cannot be quite what Schlegel is claiming. The essence of Schlegel's approach, then, hinges not on the formalism but on the epistemology of the interpretation of that formalism.

Consider the (simpler) spin zero case initially described by Bohm ${ }^{4}$ and commented on by Schlegel. (Incidentally, the situation is only less clear in the case of EPR's original example because the wave function which they choose is a particularly "mathematically pathological" function and its physical significance is not clear. ${ }^{5}$ We can, however, be certain of the falsity of the claim that in this case both the position 